\title{
Strategy for next decade aims at more creativity
}

\section{Tokyo}

THE Japanese government last week unveiled a major new report mapping out its fundamental policies for the promotion of science and technology over the next ten years. Stress is now being laid on the encouragement of creativity in science - apparently in response to Western criticism - and, along with it, greater international exchange and cooperation and the development of science in "harmony with human society".

The report, entitled Tackling changing conditions; Comprehensive and fundamental policies for long-term promotion of science and technology, is the work of the Council for Science and Technology, the highest policy-making body in the nation, whose chairman is the Prime Minister. Some 150 experts drawn from the universities, government research laboratories and private industry helped to draw it up, together with the heads of the science-based ministries and the Science Council of Japan, the academic representative body, who have permanent seats on the council.

In its 24-year history, the council has produced only 11 reports. Each has tried to set a policy framework and to define key research areas so that the ministries concerned with science can implement detailed policy in accord with the government's overall aim.

To carry out the policies suggested by the new report, increased expenditure will be required - and increased expenditure certainly seems to be what Japan has been getting. The report reveals that Japan's research and development expenditure, most of it provided by private industry, will reach 3 per cent of national income this fiscal year (over 2.8 per cent of gross national product) after four years of growth at a remarkable 0.2 per cent of national income per year. Only West Germany among the industrialized nations can claim to be spending a greater percentage of its national income on research, but the lead should pass to Japan within 2-3 years.

In calling for increased creativity, the report accepts the view that "up to now Japan has taken in foreign science and technology, improved and developed it in a highly efficient response to social and economic needs to establish its present developed (industrial) state...". But now the call is for measures to smooth the way for Japan to become one of the top nations in basic research. Several trends are seen as making this urgent: the so-called "soft revolution" - the accelerating pace of the information sciences, of which computer software development is one part, where Japan has not yet made a name for itself; the ever closer links between basic and applied research required to make possible further "miniaturization" in electronics and sophisticated control of structure and function in materials; and the increasing influence science and technology are having on human life styles.

To increase creativity, better links are called for between university and industry - noticeably absent so far in Japan. No concrete measures are suggested, however, and it is difficult to see how the present trends towards increasing reliance on private sector research will be changed. Calls are made for more efforts to train researchers in biotechnology and advanced electronics in view of an expected shortfall that could limit basic research activities.

"Internationalization" is also called for - the first time a council report has clearly done so. Foreign participation in government research projects and foreign use of government facilities are possibilities mentioned. What the report does not mention, however, is that the current trend is towards increasing competition in basic research programmes (such as the fifth generation computer project) and attempts to launch cooperative projects at the various summits have not met with success: some revolutionary steps will be needed to bring about international cooperation on any significant scale.

In contrast with the generalities of much of the report, which will require interpretation by the ministries concerned, key research themes where Japan must now make major basic research efforts are more clearly mapped out. These include research on new materials, electronics and information sciences, life sciences and earth sciences (see below). Many of the areas of materials sciences mentioned have already become the focus of long-term projects sponsored by the Science and Technology Agency and the Ministry of International Trade and Industry (see Nature 305, 373; 1983). Added here are calls for increased basic work on reaction theory and mechanisms to make possible the prediction of materials with new properties - welcome news to many university research groups.

In electronics and information sciences, areas likely to be commercialized in the near future are avoided. Stress is laid on fundamental projects such as production of the components necessary for optical circuits and eventually an optical computer, and steps towards a new science of "bioelectronics". Several electronics companies have already moved into this futuristic field, setting up groups to research, in particular, Langmuir-Blodgett films.

Life science themes to be promoted include, unsurprisingly, all the fundamental technologies that will some day have applications in biotechnology. In the earth sciences, remote sensing and the building of new satellites and data networks lie at the heart of themes aimed to make better predictions of the natural disasters - earthquakes, typhoons and floods - to which Japan is prone, and to enable natural resources, including sources of geothermal heat, to be detected more easily.

\section{Japan's strategic objectives}

AMONG the basic research themes defined the report are:

Materials science

Materials produced under extreme conditions such as ultrahigh pressure, temperature and magnetic fields-strength; artificial lattice and amorphous structures; surface properties and new ways of analysing them; interaction of materials with $\mathrm{X}$-ray, heavy and light ion beams; development of free-electron, excimer and chemical lasers; materials with mixed atomic and molecular bonding with new properties (organic superconductors); materials design by studies of unstable reaction intermediates and bonding properties, including development of associated computer stimulation and database facilities; control of form and purity as in ultrafine particles, highly ordered structures and films; composite materials and molecular hybrids; materials mimicking natural materials, such as artificial bone; new analysis and evaluation techniques. Information sciences New devices, concentrating on Josephson junctions, image processing and intelligent sensor devices; optical electronics; bioelectronics and biocomputing; knowledge management; fifth-generation computing and its connections with mathematics, symbol manipulation and psychology.

Life sciences

Gene regulation extended to cell regulation; extraction, analysis and synthesis of DNA; design, modification and synthesis of functional proteins; chromosome engineering, including modification and automatic mapping; cell and organelle modification; altering components of cells and tissues and development of the whole organism.

Earth sciences

Atmosphere-sea interaction, unusual weather conditions and typhoon generation, requiring new observation satellites and Earth-based networks; mantle dynamics, earthquakes and volcanic activity; new satellite-borne sensors and laser ranging equipment, new data networks and new Earth resource satellites.

Alun Anderson 